\title{
Divergent cyclin B1 expression and Rb/p16/ cyclin D1 pathway aberrations among pulmonary neuroendocrine tumors
}

\author{
Toru Igarashi ${ }^{1}$, Shi-Xu Jiang ${ }^{1}$, Toru Kameya ${ }^{2}$, Hisao Asamura $^{3}$, Yuichi Sato ${ }^{4}$, Kanji Nagai ${ }^{5}$ \\ and Isao Okayasu ${ }^{1}$ \\ ${ }^{1}$ Department of Pathology, Kitasato University School of Medicine, Sagamihara, Kanagawa, Japan; \\ ${ }^{2}$ Pathology Division, Shizuoka Cancer Center Hospital and Research Institute, Shizuoka, Japan; ${ }^{3}$ Department \\ of Chest Surgery, National Cancer Center Hospital, Tokyo, Japan; ${ }^{4}$ Department of Molecular Diagnostics, \\ Kitasato University School of Allied Health Sciences, Sagamihara, Japan and ${ }^{5}$ Department of Chest Surgery, \\ National Cancer Center East Hospital, Kashiwa, Japan
}

\begin{abstract}
A total of 111 pulmonary neuroendocrine tumors comprising 13 typical carcinoids, five atypical carcinoids, 44 large-cell neuroendocrine carcinomas and 49 small-cell carcinomas were immunohistochemically studied for dysregulated cyclin B1 expression and disruption of the Rb/p16/cyclin D1 pathway (Rb pathway), and the results were correlated with tumor proliferation activity and clinical outcome. Overexpression of cyclins B1 and D1, respectively, was detected in no and 15\% typical carcinoids, 20 and $20 \%$ atypical carcinoids, 84 and $32 \%$ large-cell neuroendocrine carcinomas, 84 and 10\% small-cell carcinomas. Loss of Rb and p16 expression, respectively, was observed in no and $14 \%$ typical carcinoids, no and $40 \%$ atypical carcinoids, 49 and $18 \%$ largecell neuroendocrine carcinomas, 84 and $8 \%$ small-cell carcinomas. In summary, $29 \%$ typical carcinoids, $20 \%$ atypical carcinoids, $78 \%$ large-cell neuroendocrine carcinomas and $93 \%$ small-cell carcinomas had $\mathbf{R b}$ pathway aberrations. Rb pathway aberration was mostly attributed to Rb loss in small-cell carcinomas, while p16 loss and/or cyclin D1 overexpression besides $\mathrm{Rb}$ loss also played an important role in large-cell neuroendocrine carcinomas, while cyclin D1 overexpression was the only cause of Rb pathway aberration in carcinoid tumors. Thus, both cyclin B1-associated G2/M arrest and Rb-mediated G1 arrest are consistently compromised in highgrade large-cell neuroendocrine carcinoma and small-cell carcinoma, but are generally intact or occasionally altered in carcinoid tumor; the mechanisms involved in $\mathbf{R b}$ pathway aberration among the tumor categories are different, reflecting a genetic divergence among the individual tumor categories. Cyclin B1 expression closely correlated with the Ki-67 labeling index either in the individual tumor categories or overall tumors $(P<0.0001$, $r=0.742$ ), suggesting that cyclin $B 1$ is one of the key factors regulating cell proliferation in pulmonary neuroendocrine tumors. Neither cyclins B1 and D1, Rb, p16, nor Ki-67 correlated with patient survival in individual tumor categories, suggesting that the prognostic significance of these factors is tumor-type specific. Modern Pathology (2004) 17, 1259-1267, advance online publication, 21 May 2004; doi:10.1038/modpathol.3800176
\end{abstract}

Keywords: lung cancer; neuroendocrine tumor; cyclin B1; Rb; p16; cyclin D1

Altered regulation of the cell cycle is a hallmark of human cancer cells. ${ }^{1}$ Tumor suppressors, retinoblastoma gene $(R b)$ and p53 gene-mediated cell cycle regulations involve a series of cyclins and cyclin-dependant kinases (cdk). Of the various cyclins, cyclin B1 and cyclin D1 are particularly important because the former functions at the G2/M

Correspondence: S-X Jiang, MD, Department of Pathology, Kitasato University School of Medicine, Kitasato 1-15-1, Sagamihara, Kanagawa 228-8555, Japan.

E-mail: sxjiang@med.kitasato-u.ac.jp

Received 1 March 2004; revised and accepted 8 April 2004; published online 21 May 2004 transition and is required for mitotic initiation, ${ }^{2,3}$ and inactivation of cdc2 kinase through p53induced repression of cyclin B1 is an essential step in the p53-mediated G2/M arrest,, ${ }^{4,5}$ while the latter, in a complex with cdk4 and cdk6, acts as initiator of the cell cycle by producing hyperphosphorylation of the $\mathrm{Rb}$ protein with resultant evasion of $R b$ mediated G1 arrest control. ${ }^{6,7}$ The p16 protein negatively regulates the cyclin D-dependant phosphorylation of $\mathrm{Rb}$ by replacing cyclin $\mathrm{D} 1$ in the cdk-cyclin D1 complex. ${ }^{1,7}$

Pulmonary neuroendocrine tumors embrace a spectrum from low-grade typical carcinoid, intermediate-grade atypical carcinoid to high-grade 
large-cell neuroendocrine carcinoma and small-cell carcinoma. Aberrant cyclin B1 expression was reported in various tumors and associated with a poorer prognosis in esophageal carcinoma and nonsmall-cell lung carcinoma patients. ${ }^{8,9}$ However, to the best of our knowledge, no data concerning cyclin B1 expression status within the context of pulmonary neuroendocrine tumors are currently available. Furthermore, although overexpression of cyclin D1 and loss of $\mathrm{Rb}$ or p16 expression were also reported in various solid tumors, and cyclin D1 overexpression was reported to be of prognostic importance in some tumors, ${ }^{10-19}$ aberrations in the $\mathrm{Rb} / \mathrm{p} 16 /$ cyclin D1 pathway ( $\mathrm{Rb}$ pathway) are not yet well characterized in pulmonary neuroendocrine tumors. ${ }^{20}$ Thus, the present study was carried out to analyze cyclin B1 and D1 expression status, as well as aberrations in the $\mathrm{Rb}$ pathway, and their relationship to tumor proliferation activity and clinical outcomes in a spectrum of pulmonary neuroendocrine tumors.

\section{Materials and methods}

\section{Tissue Samples}

Formalin-fixed, paraffin-embedded tissue samples of 111 surgically resected pulmonary neuroendocrine tumors from the Kitasato University Hospital, Sagamihara; the National Cancer Center Hospital, Tokyo and the National Cancer Center East Hospital, Kashiwa, Japan were studied. The cases comprised 13 typical carcinoids, five atypical carcinoids, 44 large-cell neuroendocrine carcinomas and 49 small-cell carcinomas diagnosed according to the 1999 World Health Organization criteria, ${ }^{21}$ and the histological features of most of our large-cell neuroendocrine carcinomas were detailed in a previous study. ${ }^{22}$

\section{Immunohistochemical Staining}

By the standard labeled streptavidin-biotin method, immunostaining was performed using monoclonal antibodies recognizing cyclin B1 (V152, $\times 500$, Dako, CA, USA), Rb (Rb1, $\times 50$, Dako, Denmark), p16 (NCL-p16-432, × 50, Novocastra, UK), cyclin D1 (DCS-6, $\times 200$, Dako, Denmark) and Ki-67 (MIB-1, $\times 100$, Dako, Denmark), respectively. For antigen retrieval, the slides were treated in boiling $10 \mathrm{mmol} /$ l citrate buffer ( $\mathrm{pH} \mathrm{6.0)}$ ) for 15 min for cyclin B1, or with an autoclave at $95^{\circ} \mathrm{C}$ for $1 \mathrm{~h}$ for cyclin $\mathrm{D} 1, \mathrm{Rb}$ and Ki-67, or at $121^{\circ} \mathrm{C}$ for $15 \mathrm{~min}$ for p16 stainings. After blocking of endogenous peroxidase activity with $3 \% \mathrm{H}_{2} \mathrm{O}_{2}$ in methanol for $20 \mathrm{~min}$, the sections were incubated at room temperature for $3 \mathrm{~h}$ with the individual antibodies, followed by incubation with the link antibodies and finally with the streptavidin conjugated to horseradish peroxidase of an UltraTek kit (ScyTek, Utah, USA) for $30 \mathrm{~min}$. The peroxidase activity was developed with 3,3'-diaminobenzidine and the slides were then slightly counterstained with hematoxylin, dehydrated, and mounted.

\section{Assessments of Immunohistochemical Staining}

Only nuclear staining was considered specific except for cyclin B1, for which both the nuclear and cytoplasmic stainings were assessed as specific because the cyclin B1 protein is located in the cytoplasm or nucleus during the $\mathrm{G} 2 / \mathrm{M}$ transition. Non-neoplastic fibroblasts and endothelial cells in the tumor stroma, as well as pneumocytes of adjacent normal lung tissue, served as internal positive controls for $\mathrm{Rb}$ and $\mathrm{p} 16$, or as a negative control for cyclin D1 staining. Tonsil tissue was used as positive control for both cyclin B1 and Ki-67 staining. The negative controls also included omission or replacement of the first antibodies with normal swine serum.

Labeling index (LI) of cyclin B1 was defined as the percentage of positively stained tumor cells by counting at least 1000 tumor cells in the fields with an average labeling incidence. Tumors with a $\geq 15 \%$ cyclin B1 LI were considered to show cyclin B1 overexpression, as defined in a previous report. ${ }^{8}$ Also, at least 1000 tumor cells were counted for evaluation of Ki-67, p16, Rb and cyclin D1 stainings, respectively, and to better understand their expression correlations, the tumor cells located in almost the same fields for cyclin B1 counting were counted on consecutive sections. A tumor was considered positive for p16 if more than $10 \%$ of the tumor cells were stained, as defined in a previous report. ${ }^{12}$ The $\mathrm{Rb}$ immunostaining was judged positive when the majority $(>80 \%)$ of tumor cells had nuclear staining. In the assessment of cyclin D1 staining, the staining distribution was graded as $0,1,2,3$ when none, $<10 \% ; 10-50 \%$ or $>50 \%$ tumor cells stained, and the staining intensity was graded as 1, 2, 3 when the staining was weak, moderate or strong. A tumor with a staining score (distribution score + intensity score) of 4 or greater was judged positive for cyclin D1, because so defined cyclin D1 positivity correlated closely with cyclin D1 overexpression/ amplification. ${ }^{19}$

\section{Statistical Analysis}

The expression relationships were analyzed with the $\chi^{2}$-test among $\mathrm{Rb}$ pathway factors or with the Student $t$-test between $\mathrm{Rb}$ pathway factors and Ki67. The difference in cyclin B1 or Ki-67 expression between the individual tumor categories was analyzed by Fisher's exact test. The Pearson correlation coefficient test was used to analyze the strength of association between cyclin B1 and Ki-67 expression. Patient survivals were calculated from the date of surgery, and survival curves were estimated by the Kaplan-Meier method and analyzed with the 
log-rank test. A $P$-value of less than 0.05 was considered statistically significant. All analyses were performed with StatView statistical software, version 5.0 .

\section{Results}

\section{Cyclin B1 Immunostaining}

The staining was largely cytoplasmic with a few cells stained in the nucleus (Figure $1 \mathrm{~m}-\mathrm{p}$ ). The typical carcinoids showed a few sporadic positive cells and had an LI of $0.01 \pm 0.009$. Although the atypical carcinoids generally showed more cyclin B1-stained cells than typical carcinoids $(P=0.0037)$ and had an LI of $0.08 \pm 0.076$, the positive cells were still sporadic. On the other hand, the large-cell neuroendocrine carcinomas and small-cell carcinomas had an LI of $0.236 \pm 0.091$ and $0.227 \pm 0.089$, respectively, and demonstrated many more cyclin B1-positive cells compared with the typical and atypical carcinoids $(P<0.0001$, respectively). No cyclin B1 LI difference was shown between largecell neuroendocrine carcinomas and small-cell carcinomas $(P=0.6373)$.

No typical carcinoid, while one $(20 \%)$ atypical carcinoid, 37 (84\%) large-cell neuroendocrine carcinomas and 41 (84\%) small-cell carcinomas showed cyclin B1 overexpression (defined as $\geq 15 \%$ LI), respectively.

\section{Rb, p16, and Cyclin D1 Immunostaining}

Based on the staining status of the internal positive control cells, evaluable information on $\mathrm{Rb}$ staining was available in 11 typical carcinoids, five atypical carcinoids, 43 large-cell neuroendocrine carcinomas and 45 small-cell carcinomas (Figure 1a-d). All typical and atypical carcinoids were positive for $\mathrm{Rb}$, while 21 (49\%) large-cell neuroendocrine carcinomas and $38(84 \%)$ small-cell carcinomas showed loss of $\mathrm{Rb}$ expression. There was significantly more frequent $\mathrm{Rb}$ loss in small-cell carcinomas than in large-cell neuroendocrine carcinomas $(P=0.0008)$.

Based on the staining status of the internal positive control cells again, interpretable p16 staining results were obtained in seven typical carcinoids, five atypical carcinoids, 38 large-cell neuroendocrine carcinomas and 48 small-cell carcinomas (Figure 1e-h). Absent p16 staining was observed in one (14\%) typical carcinoid, two $(40 \%)$ atypical carcinoids, seven (18\%) large-cell neuroendocrine carcinomas and four (8\%) smallcell carcinomas. Although p16 loss was more frequent in large-cell carcinomas than in small-cell carcinomas, the difference was not statistically significant $(P=0.08)$. There was also no difference in p16 loss incidence between typical and atypical carcinoids $(P=0.3159)$.
Two (15\%) typical carcinoids, one (20\%) atypical carcinoid, $14(32 \%)$ large-cell neuroendocrine carcinomas and five $(10 \%)$ small-cell carcinomas had cyclin D1 staining scores of or greater than 4; thus, these tumors were classed as cyclin D1 positive (Figure 1i-1). Cyclin D1 expression was significantly more frequent in large-cell neuroendocrine carcinomas than in small-cell carcinomas $(P=0.0098)$, while no difference was shown between typical and atypical carcinoids $(P=0.1616)$.

\section{Aberration of the Overall Rb Pathway}

Taking the Rb, p16 and cyclin D1 staining results together, six Rb pathway phenotypes were noted in the tumors as detailed in Table 1 . As either loss of $\mathrm{Rb}$ or p16 expression, or overexpression of cyclin D1, are considered an aberration of the overall $\mathrm{Rb}$ pathway with the $\mathrm{Rb}^{+} / \mathrm{p} 16^{+} /$cyclin $\mathrm{D} 1^{-}$phenotype as normal, three (43\%) typical carcinoids, three $(60 \%)$ atypical carcinoids, $31 \quad(86 \%)$ large-cell neuroendocrine carcinomas and 42 (95\%) small-cell carcinomas were judged to have an abnormal $\mathrm{Rb}$ pathway phenotype (Table 1). However, because p16 maintains $\mathrm{Rb}$ in a hypophosphorylation-active form through its preferential binding to cdks 4 and 6 to prevent their association with cyclin $\mathrm{D} 1,^{1,7}$ it is reasonable to deduce that the $\mathrm{Rb}$ pathway is functionally intact when p16 is absent but without cyclin D1 overexpression. Thus, two (29\%) typical carcinoids, one $(20 \%)$ atypical carcinoid, $28(78 \%)$ large-cell neuroendocrine carcinomas and 41 (93\%) small-cell carcinomas were judged to have practical $\mathrm{Rb}$ pathway disruption. Rb pathway aberration was much more frequent in large-cell neuroendocrine carcinoma/small-cell carcinoma than in carcinoid tumor $(P<0.0001)$, while no difference could be found between typical carcinoid and atypical carcinoid $(P=0.9999)$ or between large-cell neuroendocrine carcinoma and small-cell carcinoma $(P=0.0961)$ (Table 1).

As shown in Table $1, \mathrm{Rb}$ pathway aberration in small-cell carcinomas was largely attributed to direct loss of $\mathrm{Rb}$ expression. Although $\mathrm{Rb}$ loss was still the major cause, overexpression of cyclin D1 and loss of p16 expression also accounted for a high percentage of $\mathrm{Rb}$ pathway aberration in large-cell neuroendocrine carcinomas. On the other hand, overexpression of cyclin D1 was the only cause of practical $\mathrm{Rb}$ pathway abnormality in the carcinoid tumors.

\section{Ki-67 Expression and Its Relationship with Cyclin B1, Rb, p16 and Cyclin D1 Expression}

The Ki-67 LI was $0.013 \pm 0.001$ in typical carcinoids, $0.086 \pm 0.084$ in atypical carcinoids, $0.522 \pm 0.16$ in large-cell neuroendocrine carcinomas and $0.546 \pm 0.113$ in small-cell carcinomas, respectively. There was a significantly higher Ki-67 LI in 

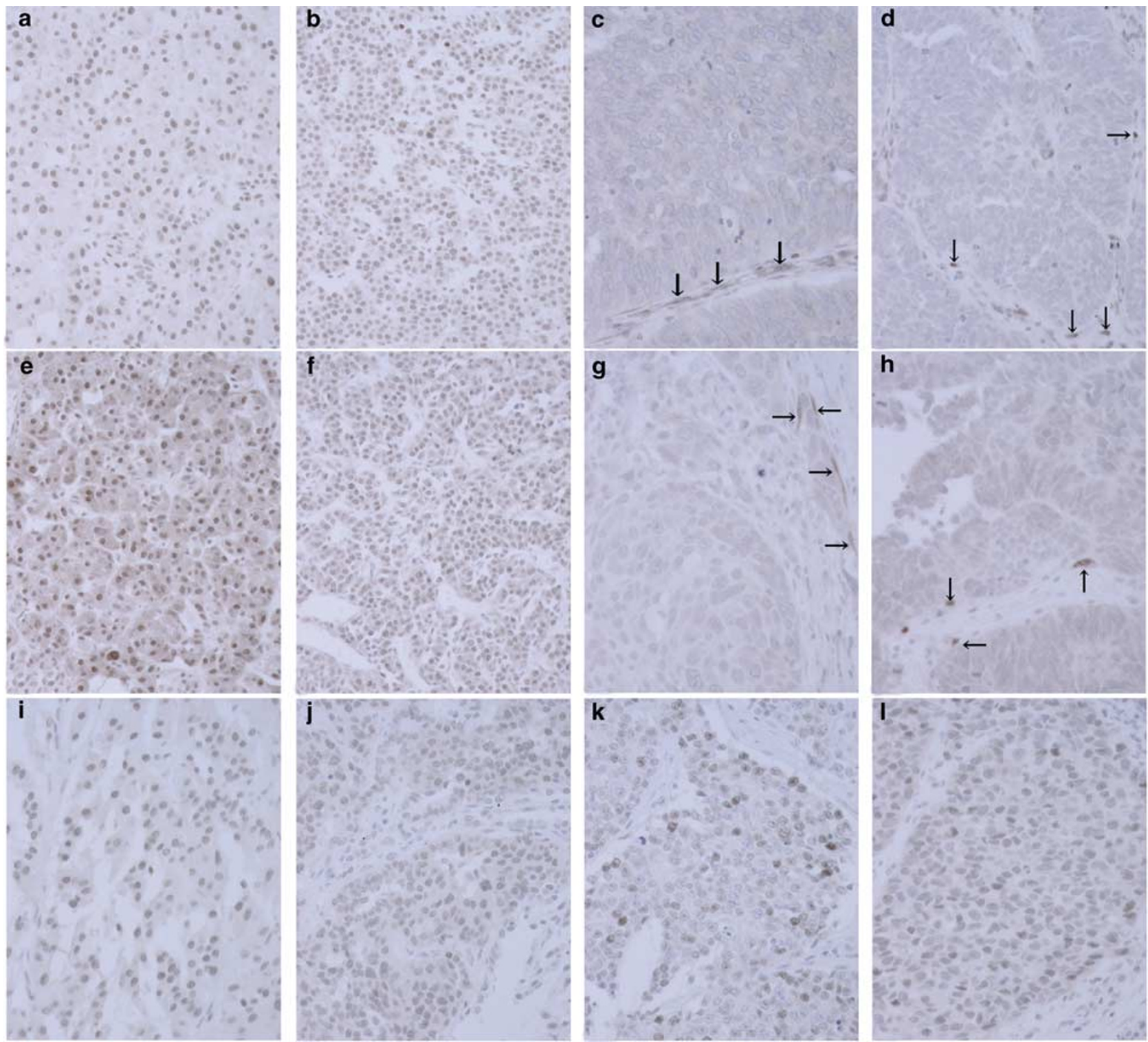

Figure 1 Representative Rb (a-d), p16 (e-h), cyclin D1 (i-l), cyclin B1 (m-p) and Ki-67 (q-t) immunostaining results. Nuclear Rb staining and p16 staining in most tumor cells of typical carcinoid (a, e) and atypical carcinoid (b, f), and completely absent Rb staining or p16 staining in the tumor cells of large-cell neuroendocrine carcinoma $(\mathbf{c}, \mathbf{g})$ and small-cell carcinoma $(\mathbf{d}, \mathbf{h})$, and note the positive staining in the stromal fibroblasts (arrow). Representative nuclear staining of cyclin D1 in typical carcinoid (i), atypical carcinoid (j), large-cell neuroendocrine carcinoma (k) and small-cell carcinoma (l). There are many more cyclin B1-stained cells and Ki-67-labeled cells in largecell neuroendocrine carcinoma (o, s) and small-cell carcinoma (p, t) than in typical carcinoid (m, q) and atypical carcinoid (n, r), as well as in atypical carcinoid than in typical carcinoid. Although there are generally more Ki-67-labeled cells than cyclin B1-stained cells in individual tumors, note the general tendency of a parallel between cyclin B1-postive cells (m-p) and Ki-67-labeled cells (q-t) in number and distribution on consecutive sections.

large-cell neuroendocrine carcinomas and small-cell carcinomas than in typical and atypical carcinoids $(P<0.0001$, respectively), as well as in atypical carcinoids compared to typical carcinoids $(P=0.0054)$, while no difference could be found between large-cell neuroendocrine carcinomas and small-cell carcinomas $(P=0.4031)$.

In individual tumors, Ki-67-postive cells generally paralleled cyclin B1-labeled cells in numbers and distributions on consecutive sections, although there were generally more Ki-67-positive cells than cyclin B1-stained cells (Figure 1q-t). Statistical analyses also revealed a close correlation between Ki-67 and cyclin B1 expression either in the individual tumor categories or in the overall tumors $(P<0.0001, r=0.742)$ (Figure 2). Ki-67 expression correlated with p16 expression in carcinoid tumors $(P<0.01)$, but not in small-cell carcinomas or in large-cell neuroendocrine carcinomas. Although there was also a significantly higher Ki-67 LI in Rb-negative than in Rb-positive tumors within the overall tumors $(P<0.01)$, as could be expected, it was apparently due to the fact that all Rb-negative tumors were high-grade tumors, large-cell 

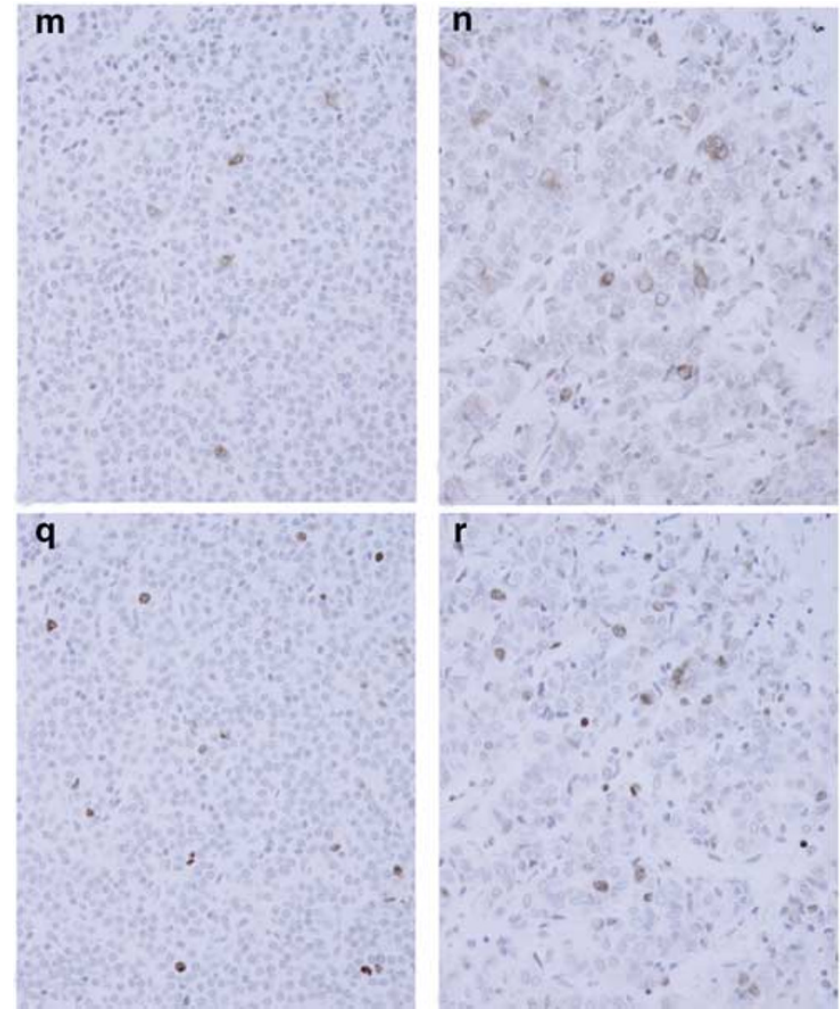
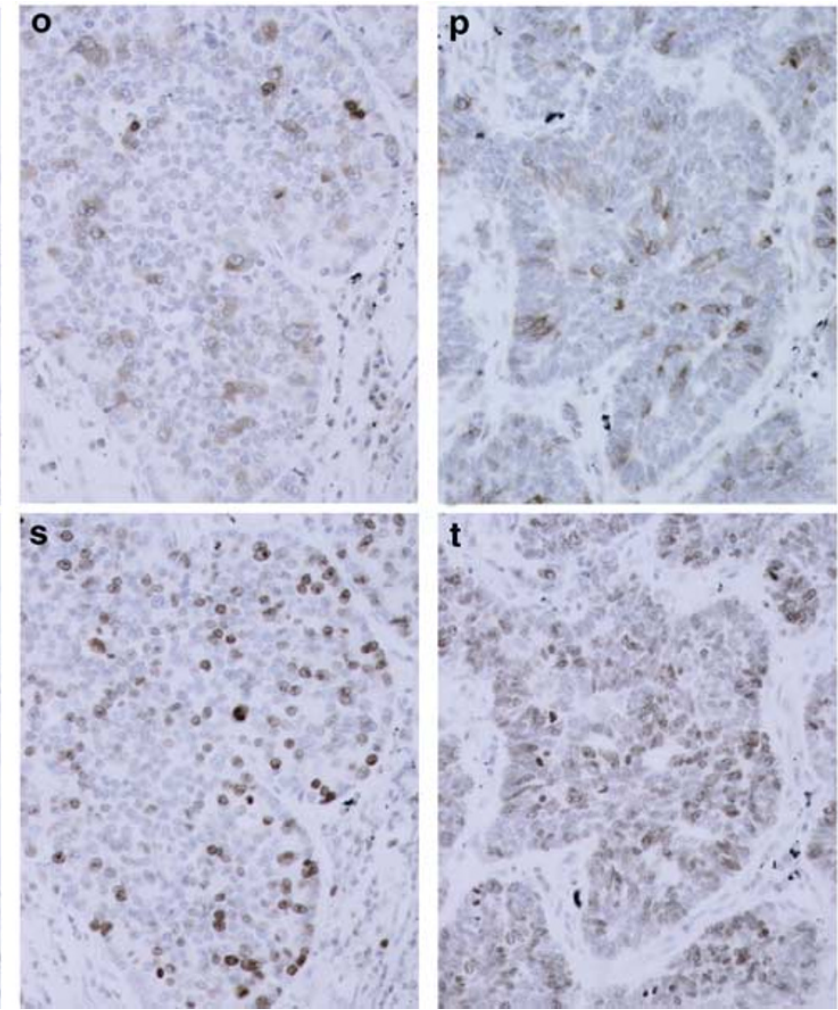

Figure 1 Continued.

Table $1 \mathrm{Rb} / \mathrm{p} 16 /$ cyclin D1 (Rb pathway) phenotypes in 92 pulmonary NE tumors

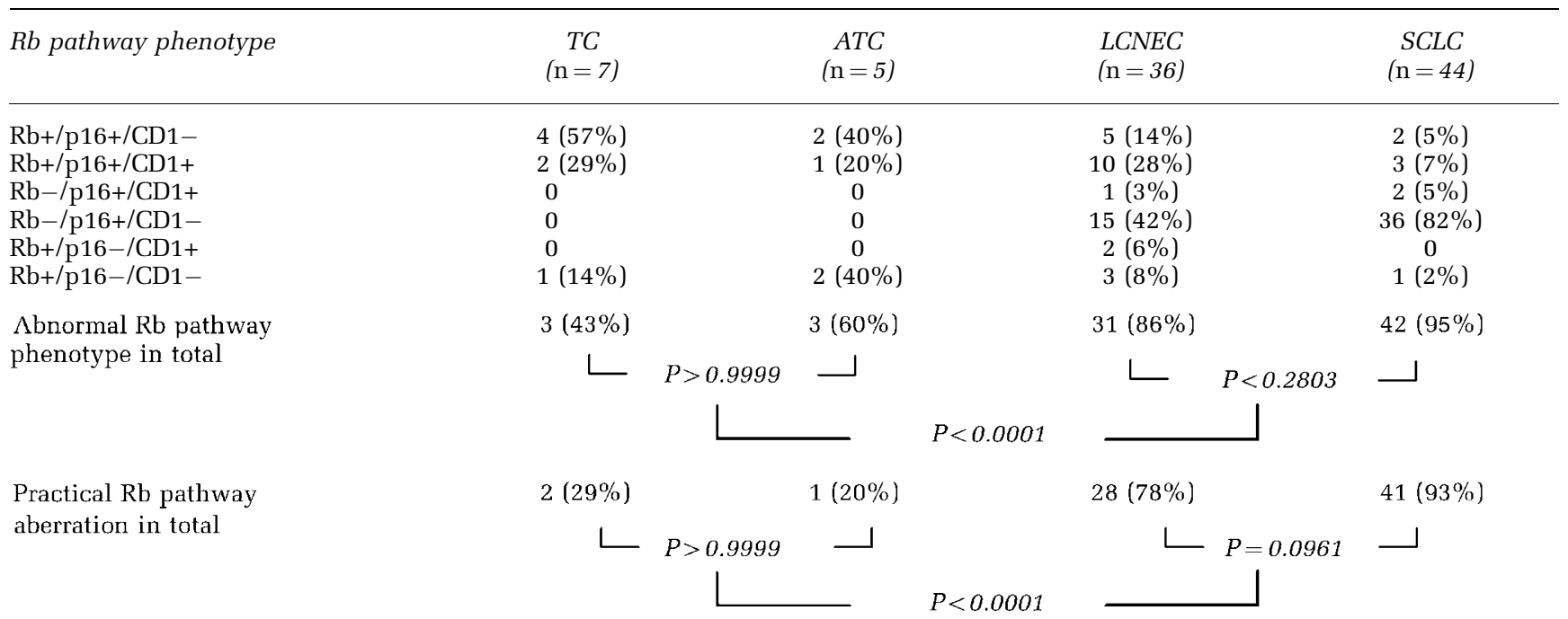

TC, typical carcinoid; ATC, atypical carcinoid; LCNEC, large-cell neuroendocrine carcinoma; SCLC, small-cell carcinoma; CD1, cyclin D1.

neuroendocrine carcinoma and small-cell carcinoma. No correlation could be found between Ki-67 and $\mathrm{Rb}$ expression in the individual tumor categories. Ki-67 expression and cyclin D1 expression did not correlate with each other either in the individual tumor categories or in overall tumors $(P<0.37)$.

\section{Survival Analysis}

All the typical carcinoid patients survived, while two atypical carcinoid, 20 large-cell neuroendocrine carcinoma and 20 small-cell carcinoma patients succumbed to their diseases, respectively. Owing to the fact that the vast majority of tumors with high 
a

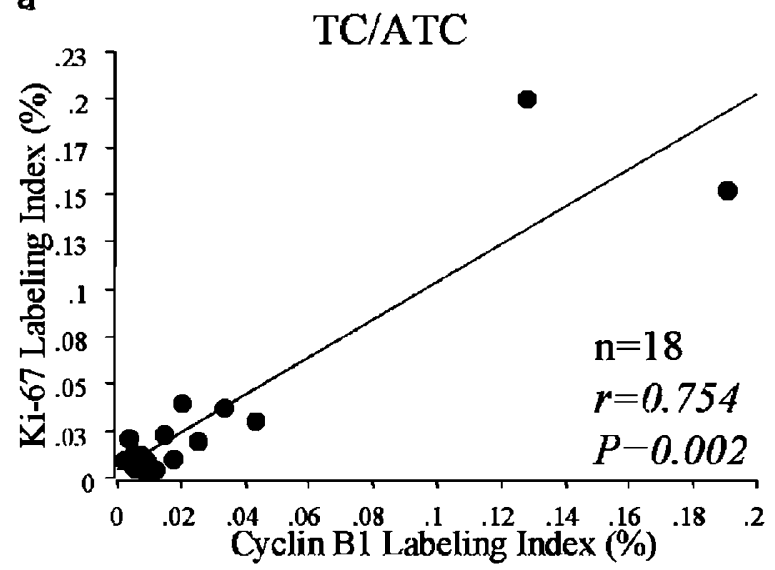

c

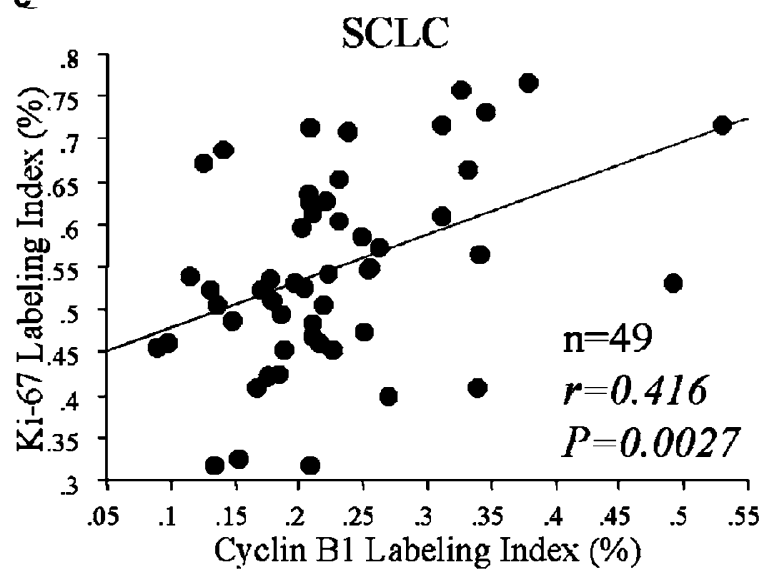

b
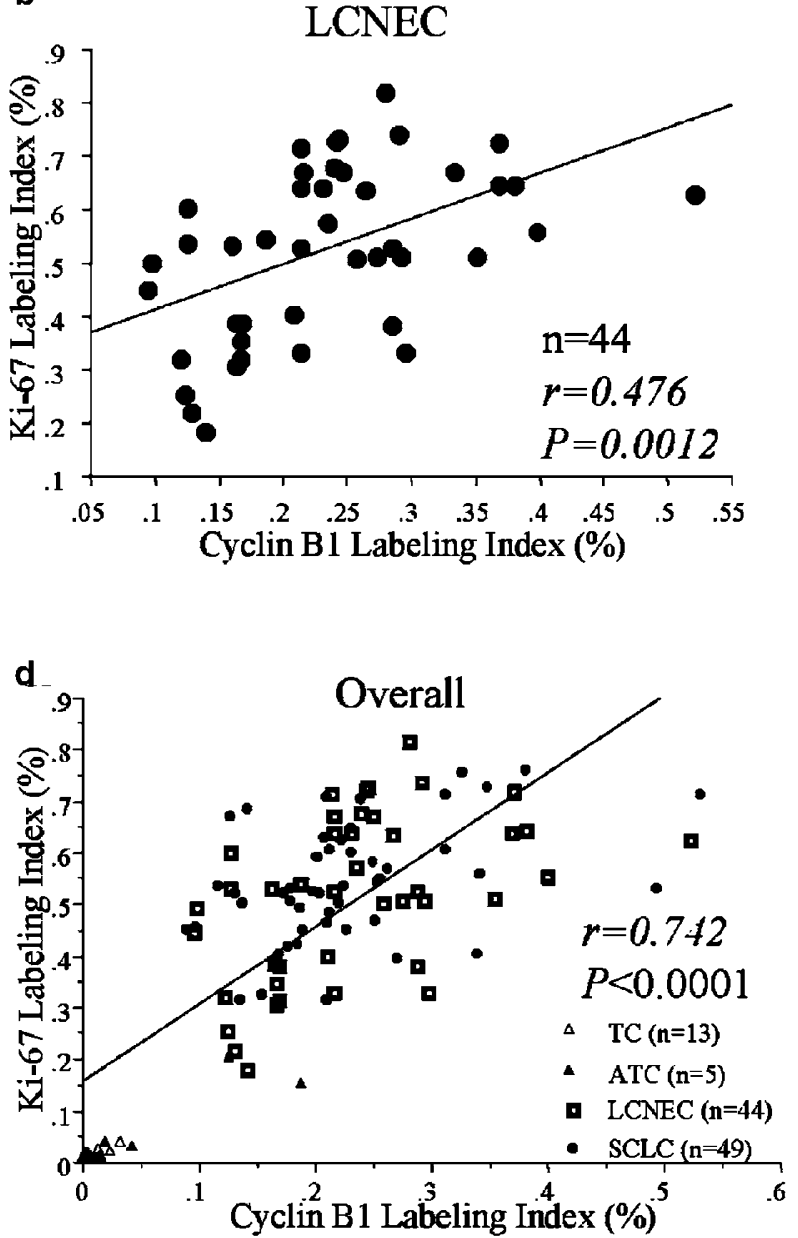

Figure 2 Cyclin B1 expression closely correlates with Ki-67 expression either in typical carcinoid/atypical carcinoid (TC/ATC) (a), largecell neuroendocrine carcinoma (LCNEC) (b) and small-cell carcinoma (SCLC) (c) or overall tumors (d) (Pearson's correlation coefficient test).

cyclin B1 and Ki-67 LI, and all tumors with Rb loss, were large-cell neuroendocrine carcinoma and small-cell carcinoma, higher cyclin B1 and Ki-67 LIs and $\mathrm{Rb}$ loss correlated with a worse prognosis within overall tumors. No such correlations, however, were found within the individual tumor categories. Neither p16 nor cyclin D1 expression status correlated with patient survival, even within overall tumors.

\section{Discussion}

The spectrum of pulmonary neuroendocrine tumors embraces typical carcinoid, atypical carcinoid, large-cell neuroendocrine carcinoma and small-cell carcinoma, with typical carcinoid and small-cell carcinoma representing the two extremes of malignancy. ${ }^{21,23}$ Repeated studies have shown that carcinoid tumors were genetically divergent from high-grade large-cell neuroendocrine carcinoma and small-cell carcinoma, and had no, or only occasional, genetic events such as p53 mutation and $R b$ inactivation. ${ }^{13,14,24-28}$ In the present study, we demonstrated for the first time that cyclin B1 overexpression was also a very frequent event in high-grade neuroendocrine tumors and was found in most (84\%) large-cell neuroendocrine carcinomas and small-cell carcinomas, while no typical carcinoid and only one $(20 \%)$ atypical carcinoid overexpressed cyclin B1, indicating that regulation of cyclin B1 expression and G2/M arrest are consistently compromised in high-grade pulmonary neuroendocrine tumors, but are intact in typical carcinoid or only occasionally compromised in atypical carcinoid. The high frequency of cyclin B1 dysregulation in both the large-cell neuroendocrine carcinoma and small-cell carcinoma may reflect a similar alteration in cell cycle regulation at the G2/M transition, despite their distinct morphologies.

Studies have shown that p53 also controls the G2/ $M$ checkpoint besides its key role in G1 arrest, and 
inactivation of cdc2 kinase through repression of cyclin B1 is an essential step in p53-mediated G2/M arrest. $^{4,5}$ It was well documented that the majority of large-cell neuroendocrine carcinoma and small-cell carcinoma harbored p53 abnormalities, while p53 was almost intact in carcinoid tumor. ${ }^{24-27}$ Thus, it is very likely that the frequent cyclin B1 overexpression in high-grade pulmonary neuroendocrine tumors results from their frequent p53 alterations with consequent loss of p53-mediated cyclin B1 repression.

In the present study, practical Rb pathway aberration was observed in 29\% typical carcinoids, $20 \%$ atypical carcinoids, $78 \%$ large-cell neuroendocrine carcinomas and 93\% small-cell carcinomas, in keeping with the results of a recent study. ${ }^{20}$ These results together demonstrate that $\mathrm{Rb}$ pathwaymediated G1 arrest is also frequently compromised in large-cell neuroendocrine carcinoma and smallcell carcinoma, but is rarely affected in carcinoid tumor. Loss of Rb or p16 or overexpression of cyclin $\mathrm{D} 1$ accounts for $\mathrm{Rb}$ pathway aberrations in large-cell neuroendocrine carcinoma/small-cell carcinoma, while cyclin D1 overexpression is the only cause of $\mathrm{Rb}$ pathway aberration in carcinoid tumor.

Despite their quite different morphologies, largecell neuroendocrine carcinoma and small-cell carcinoma share many genetic alterations such as frequent p53 mutation, $R b$ inactivation and dysregulated bcl-2 expression. ${ }^{13,14,25,27-29}$ On the other hand, divergence in chromosomal aberrations was also observed between them, ${ }^{30}$ and the specific genetic alterations for either large-cell neuroendocrine carcinoma or small-cell carcinoma remain to be further characterized. In the present study, both large-cell neuroendocrine carcinoma and small-cell carcinoma showed almost equally frequent $\mathrm{Rb}$ pathway aberration. However, the mechanisms involved in $\mathrm{Rb}$ pathway aberration were distinct between them. Direct $\mathrm{Rb}$ loss was much more frequent in small-cell carcinoma than in large-cell neuroendocrine carcinoma $(P<0.008)$, while cyclin D1 overexpression was much more common in the latter $(P<0.0001)$. There was also an obvious tendency for more frequent p16 loss in large-cell neuroendocrine carcinoma than in small-cell carcinoma $(P<0.08)$. These results might reflect a genetic difference between large-cell neuroendocrine carcinoma and small-cell carcinoma, and a similarity between large-cell neuroendocrine carcinoma and non-small-cell lung carcinoma. ${ }^{15,31-33}$

Ki-67 is a well-established marker of cell proliferation activity and its expression is not phase specific in the cell cycle. In the present study, the mean proliferation rate determined by Ki-67 LI was 1.3, 8.6, 52.2 and $54.6 \%$ in typical carcinoids, atypical carcinoids, large-cell neuroendocrine carcinomas and small-cell carcinomas, respectively. Both large-cell neuroendocrine carcinomas and smallcell carcinomas demonstrated significantly higher proliferation activity than typical and atypical carcinoids $(P<0.0001)$, and the same was true for atypical carcinoids than typical carcinoids $(P<0.01)$, while there was no significant difference in Ki-67 expression between large-cell neuroendocrine carcinomas and small-cell carcinomas $(P=0.4031)$, in keeping with previous studies. ${ }^{34,35}$ These results reflect the low-grade biological features of typical carcinoid, the less aggressive behavior of atypical carcinoid and the highly malignant nature of large-cell neuroendocrine carcinoma and small-cell carcinoma.

Correlations of varying degrees between cyclin B1 and Ki-67 expressions were observed in some tumors, including non-small-cell lung carcinoma, ${ }^{8,36}$ while no correlation was found in others. ${ }^{37}$ In the present study, Ki-67-positive cells generally paralleled cyclin B1-stained cells in individual tumors on serial sections, and statistical analysis also demonstrated a very close correlation between cyclin B1 and Ki-67 expressions either in the individual tumor categories or overall tumors $(P<0.0001, r=0.742)$, suggesting that cyclin B1 is one of the key factors regulating cell proliferation in pulmonary neuroendocrine tumors, and that aberrant cyclin B1 expression may be critical for promoting cell cycle progression and unrestrained tumor cell proliferation. A recent study showed that Ki-67 played a role in the disintegration and reformation of nucleolus, and thereby in entry into and exit from the $\mathrm{M}$ phase of the cell cycle depending on cyclin B1 expression. ${ }^{38}$

Either loss of $\mathrm{Rb}$ or $\mathrm{p} 16$, or overexpression of cyclin D1 correlated with an increased proliferation fraction in some tumors, ${ }^{17,33}$ while no such correlation was seen in others. ${ }^{39,40}$ Significantly higher Ki-67 LI was observed in Rb-negative than in Rbpositive tumors within the overall tumors in the present study. As expected, it was apparently due to the fact that all Rb-negative tumors were high-grade tumors, large-cell neuroendocrine carcinoma and small-cell carcinoma. No correlation between Ki-67 and $\mathrm{Rb}$ expressions could be found within the individual tumor categories. p16 expression correlated with Ki-67 expression in carcinoid tumors, but not in large-cell neuroendocrine carcinomas or small-cell carcinomas. However, due to the very small number (three cases) of p16-negative carcinoid tumors, the significance of this correlation remains to be further studied based on larger samples. Cyclin D1 overexpression did not correlate with tumor proliferation activity in either the individual tumor subtypes or the overall tumors.

Overexpression of cyclin B1 or D1, or loss of $\mathrm{Rb}$ or p16, correlated with shortened survival in some tumors, including non-small-cell lung carcinoma ${ }^{8-10,18,36}$ while other studies showed no influence on patient survival. ${ }^{15,32,39,40}$ It was also reported that cyclin D1 overexpression was a favorable prognostic factor in non-small-cell lung carcinoma. ${ }^{16}$ In the present study, none of these factors correlated with patient survivals within the 
individual tumor categories, suggesting that their prognostic significance is tumor-type specific.

In summary, the present study demonstrated, for the first time, that cyclin B1 expression is very frequently dysregulated in high-grade pulmonary neuroendocrine tumor, but is intact in typical carcinoid or only occasionally compromised in atypical carcinoid, and that cyclin B1 is one of the critical key factors regulating cell proliferation in pulmonary neuroendocrine tumors. $\mathrm{Rb}$ pathway disruption is also a common event in high-grade pulmonary neuroendocrine tumor, but occurs only occasionally in carcinoid tumor; the mechanisms involved in $\mathrm{Rb}$ pathway disruption in large-cell neuroendocrine carcinoma and small-cell carcinoma, as well as in carcinoid tumor, are different. Neither overexpression of cyclins B1 and D1, nor loss of $\mathrm{Rb}$ or p16 influences the survival of patients within the individual categories of pulmonary neuroendocrine tumors.

\section{Acknowledgements}

This work was supported by Grants from the Ministry of Education, Culture, Sports, Science and Technology (15590314 and High-tech Research Center) and from the Ministry of Health, Labor and Welfare (11-19 and 15-15), Japan.

\section{References}

1 Sherr CJ. Cancer cell cycles. Science 1996;274: 1672-1677.

2 King RW, Jackson PK, Kirschner MW. Mitosis in transition. Cell 1994;79:563-571.

3 Jin P, Hardy S, Morgan DO. Nuclear localization of cyclin B1 controls mitotic entry after DNA damage. J Cell Biol 1998;141:875-885.

4 Innocente SA, Abrahamson JLA, Cogswell JP, et al. p53 regulates a $G_{2}$ checkpoint through cyclin B1. Proc Natl Acad Sci USA 1999;96:2147-2152.

5 Park M, Chae HD, Yun J, et al. Constitutive activation of cyclin B1-associated cdc2 kinase overrides p53-mediated $\mathrm{G}_{2}-\mathrm{M}$ arrest. Cancer Res 2000;60: $542-545$.

6 Resnitzky D, Gossen M, Bujard H, et al. Acceleration of the G1/S phase transition by expression of cyclins D1 and $E$ with an inducible system. Mol Cell Biol 1994;14:1669-1679.

7 Weinberg RA. The retinoblastoma protein and cell cycle control. Cell 1995;81:323-330.

8 Soria JC, Jang SJ, Khuri FR, et al. Overexpression of cyclin B1 in early-stage non-small cell lung cancer and its clinical implication. Cancer Res 2000;60: 4000-4004.

9 Takeno S, Noguchi T, Kikuchi R, et al. Prognostic value of cyclin B1 in patients with esophageal squamous cell carcinoma. Cancer 2002;94:2874-2881.

10 Akervall JA, Michalides RJAM, Mineta $\mathrm{H}$, et al. Amplification of cyclin D1 in squamous cell carcinoma of the head and neck and the prognostic value of chromosomal abnormalities and cyclin D1 overexpression. Cancer 1997;79:380-389.

11 Betticher DC, Heighway J, Hasleton PS, et al. Prognostic significance of CCND1 (cyclin D1) overexpression in primary resected non-small-cell lung cancer. $\mathrm{Br}$ J Cancer 1996;73:294-300.

12 Gazzeri S, Gouyer V, Vour'ch C, et al. Mechanisms of p16 ${ }^{\text {INK4A }}$ inactivation in non small-cell lung cancers. Oncogene 1998;16:497-504.

13 Gouyer V, Gazzeri S, Bolon I, et al. Mechanism of retinoblastoma gene inactivation in the spectrum of neuroendocrine lung tumors. Am J Respir Cell Mol Biol 1998;18:188-196.

14 Cagle PT, el-Naggar AK, Xu HJ, et al. Differential retinoblastoma protein expression in neuroendocrine tumors of the lung. Potential diagnostic implications. Am J Pathol 1997;150:393-400.

15 Brambilla E, Moro D, Gazzeri S, et al. Alterations of expression of Rb, p16 $6^{\text {INK4A }}$ and cyclin D1 in non-small cell lung carcinoma and their clinical significance. J Pathol 1999;188:351-360.

16 Mishina T, Dosaka-Akita H, Kinoshita I, et al. Cyclin D1 expression in non-small-cell lung cancers: its association with altered p53 expression, cell proliferation and clinical outcome. Br J Cancer 1999;80: 1289-1295.

17 Mate JL, Ariza A, Aracil C, et al. Cyclin D1 overexpression in non-small cell lung carcinoma: correlation with Ki67 labelling index and poor cytoplasmic differentiation. J Pathol 1996;180:395-399.

18 Nozoe T, Korenage D, Kabashima A, et al. Significance of cyclin B1 expression as an independent prognostic indicator of patients with squamous cell carcinoma of the esophagus. Clin Cancer Res 2002;8: 817-822.

19 Gillett C, Fantl V, Smith R, et al. Amplification and overexpression of cyclin D1 in breast cancer detected by immunohistochemical staining. Cancer Res 1994; 54:1812-1817.

20 Beasley MB, Lantuejoul S, Abbondanzo S, et al. The p16/cyclin D1/Rb pathway in neuroendocrine tumors of the lung. Hum Pathol 2003;34:136-142.

21 Travis WC, Colby TV, Corrin B, et al, (in collaboration with Sobin LH and pathologists from 14 countries). The World Health Organization Histological Typing of Lung and Pleural Tumors. 3rd edn. Springer: Tokyo, 1999.

22 Jiang SX, Kameya T, Shoji $\mathrm{M}$, et al. Large cell neuroendocrine carcinoma of the lung. A histologic and immunohistochemical study of 22 cases. Am J Surg Pathol 1998;22:526-537.

23 Travis WD, Rush W, Flieder DB, et al. Survival analysis of 200 pulmonary neuroendocrine tumors with clarification of criteria for atypical carcinoid and its separation from typical carcinoid. Am J Surg Pathol 1998;22:934-944.

24 D’Amico D, Carbone D, Mitsudomi T, et al. High frequency of somatically acquired p53 mutations in small cell lung cancer cell lines and tumors. Oncogene 1992;7:339-346.

25 Jiang SX, Kameya T, Shinada J, et al. The significance of frequent and independent p53 and bcl-2 expression in large-cell neuroendocrine carcinomas of the lung. Mod Pathol 1999;12:362-369.

26 Lohmann DR, Fesseler B, Putz B, et al. Infrequent mutation of the p53 gene in pulmonary carcinoid tumors. Cancer Res 1993;53:5797-5801. 
27 Onuki N, Wistuba II, Travis WD, et al. Genetic changes in the spectrum of neuroendocrine lung tumors. Cancer 1999;85:600-607.

28 Dosaka-Akita H, Cagle PT, Hiroumi H, et al. Differential retinoblastoma and $\mathrm{p} 16^{\mathrm{INK} 4 \mathrm{~A}}$ protein expression in neuroendocrine tumors of the lung. Cancer 2000;88:550-556.

29 Jiang SX, Kameya T, Sato Y, et al. Bcl-2 protein expression in lung cancer and close correlation with neuroendocrine differentiation. Am J Pathol 1996;148: 837-846.

30 Ullmann R, Petzmann S, Sharma A, et al. Chromosomal aberrations in a series of large-cell neuroendocrine carcinomas: unexpected divergence from small-cell carcinoma of the lung. Hum Pathol 2001; 32:1059-1063.

31 Kratzke RA, Greatens TM, Rubins JB, et al. Rb and p16 ${ }^{\text {INK4A }}$ expression in resected non-small cell lung tumors. Cancer Res 1996;56:3415-3420.

32 Kinoshita I, Dosaka-Akita H, Mishina T, et al. Altered p16 ${ }^{\mathrm{INK} 4}$ and retinoblastoma protein status in non-small cell lung cancer: potential synergistic effect with altered p53 protein on proliferative activity. Cancer Res 1996;56:5557-5562.

33 Tanaka H, Fujii Y, Hirabayashi H, et al. Disruption of the RB pathway and cell-proliferative activity in nonsmall cell lung cancers. Int J Cancer 1998;79:111-115.
34 Bohm J, Koch S, Gais P, et al. Prognostic value of MIB-1 in neuroendocrine tumors of the lung. J Pathol 1996; 178:402-409.

35 Arbiser ZK, Arbiser JL, Cohen C, et al. Neuroendocrine lung tumors: grade correlates with proliferation but not angiogensis. Mod Pathol 2001;14:1195-1199.

36 Mashal RD, Lester S, Corless C, et al. Expression of cell cycle-regulated proteins in prostate cancer. Cancer Res 1996;56:4159-4163.

37 Korenaga D, Takesue F, Yasuda M, et al. The relationship between cyclin B1 overexpression and lymph node metastasis in human colorectal cancer. Surgery 2002;131:S114-S120.

38 Schmidt MH, Broll R, Bruch HP, et al. The proliferation marker pKi-67 organizes the nucleous during the cell cycle depending on Ran and cyclin B. J Pathol 2003;199:18-27.

39 Dosaka-Akita H, Hommura F, Mishina T, et al. A riskstratification model of non-small cell lung cancers using cyclin E, Ki-67, and ras p21: different roles of G1 cyclins in cell proliferation and prognosis. Cancer Res 2001;61:2500-2504.

40 Konstantinidou AE, Korkolopoulou P, Vassilopoulos I, et al. Reduced retinoblastoma gene protein to Ki-67 ratio is an adverse prognostic indicator for ovarian adenocarcinoma patients. Gynecol Oncol 2003;88: 369-378. 